\title{
Abstract
}

\section{Investigating Homeopathic Potencies with Membrane Bound Solvatochromic Dyes}

\section{Steven Cartwright}

Cherwell Innovation Centre, Oxford

steven.cartwright@oxford-homeopathy.org.uk - https://orcid.org/0000-0001-7798-9070

Background Solvatochromic dyes have demonstrated themselves to be useful probes in the molecular-level study of homeopathic potencies. The range of dyes available, and their broad division into two main electronic structural groups, is permitting a detailed investigation of the fundamental nature of potencies. The immobilisation of solvatochromic dyes on transparent membranes takes these investigations to a new level of investigative precision. Aims To attach as many different solvatochromic dyes as possible to triacetylcellulose membranes, and where successful, to observe in detail the spectroscopic changes that occur on exposure to potencies. Immobilisation of dyes onto membranes de-couples the initial dye-potency interaction from later aggregation processes, thereby allowing a host of questions to be asked about what exactly potencies are doing to solvatochromic dyes and in turn indicating what the identities of potencies are likely to be. Methodology A number of methods have been explored for covalently linking dyes to membranes, which at the same time maintain the integrity of the solvatochromic chromophore. Immobilised dyes, in contrast to dyes in solution, behave differently, which means water-insoluble dyes for instance, can be used under a range of solution conditions that were not possible previously. Results and discussion Results from three positively solvatochromic dyes show that potencies cause a bathochromic shift in their spectra, confirming what has been seen previously with encapsulated dyes but with greater clarity. Results can be explained by invoking a polarising effect of potencies and differential stabilisation of the dyes' ground and excited electronic states. The kinetics of the dye-potency interaction indicate the effect of potency reaches a maximum and then declines. Conclusion Immobilisation of solvatochromic dyes presents a significant step forward in the ability to investigate homeopathic potencies at the physicochemical level.

\section{Keywords: solvatochromic dyes, immobilisation, polarisation, kinetics}

(C) International Journal of High Dilution Research.

Not for commercial purposes. 